\title{
Diversidad taxonómica y genética del sitio prioritario Península de Hualpén, Región del Bío-Bío, Chile. Implicancias para la conservación
}

\section{Taxonomic and genetic diversity of the priority site Hualpen Peninsula, Región Bío-Bío, Chile. Implications for conservation}

\author{
Glenda Fuentes $^{1 *}$, Anita Cisternas ${ }^{2}$, Graciela Valencia ${ }^{3}$, Maritza Mihoč $^{3}$, Eduardo Ruiz ${ }^{1}$, Rodrigo \\ Hasbún ${ }^{4}$, Sofía Valenzuela ${ }^{4} \&$ Carlos M. Baeza ${ }^{1}$ \\ 1Departamento de Botánica Facultad de Ciencias Naturales y Oceanográficas, Universidad de Concepción, Casilla 160-C, \\ Concepción, Chile. \\ 2Plant Biology and Conservation, Weinberg College of Arts and Science. Northwestern University, O.T. Hogan Hall, 2205 Tech \\ Drive 60208 Evanston, IL. USA. \\ ${ }^{3}$ Instituto de Ecología y Biodiversidad (IEB): Dirección: Las Palmeras 3425, Ñuñoa, Santiago, Chile. \\ ${ }^{4}$ Departamento de Silvicultura, Facultad de Ciencias Forestales, Universidad de Concepción. Victoria 631, Barrio Universitario, \\ Casilla 160-C, Correo 3, Concepción, Chile. \\ *glfuente@udec.cl
}

\section{RESUMEN}

Dentro de los componentes de la diversidad biológica se encuentran la diversidad taxonómica y genética. El análisis de ambos resulta indispensable para la elaboración de estrategias de manejo y conservación de áreas prioritarias para la conservación. La península de Hualpén alberga uno de los últimos relictos de bosque costero de la Región del Bío-Bío, concentrado en la Estación de Biología Terrestre (EBT) cedida en comodato a la Universidad de Concepción, por parte de la gobernación de Concepción. En este estudio se evaluó la variabilidad taxonómica y genética de la península con el fin de contribuir al desarrollo de estrategias de conservación y futuro desarrollo de planes de manejo en esta. Para ello se cuantificó la riqueza de especies a lo largo de 20 transectos, localizados dentro de la península. A su vez, se evaluó la diversidad genética con marcadores AFLP para cinco especies no relacionadas filogenéticamente. Se encontró un total de 90 especies, donde el $78 \%$ son nativas y el $22 \%$ son especies introducidas. La riqueza de especies nativas se concentró en la EBT, presentando diferencias significativas con el resto de los sitios muestreados. El análisis de los marcadores moleculares mostró valores de diversidad genética congruentes con los reportados para especies de similares características biológicas. Además, los resultados de diversidad genética para las especies estudiadas concuerdan con los reportados en otros sitios de su distribución geográfica. Por lo tanto, la EBT concentra altos valores de diversidad específica y genética. Esto podría ser el reflejo de la protección del sitio por parte de la entidad administradora. Considerando la presencia de especies en peligro dentro de la estación biológica y la riqueza de especies en el área, se aconseja incluir a la EBT y algunos lugares aledaños en el sistema de áreas protegidas por el Estado.

Palabras clave: Relicto nativo, riqueza de especies, variabilidad genética, conservación.

\begin{abstract}
Taxonomic and genetic diversity are among the components of biodiversity. Both components need to be taken in consideration to establish management and conservation strategies in high-priority areas for conservation. Pedro del Rio Zañartu park in the peninsula of Hualpen, contains one of the last relicts of the coastal forest of the Bio-Bio Region, mainly concentrated in the Terrestrial Biological Station (EBT) assigned to the University of Concepcion near to the city of Concepcion. In this study, we evaluated both taxonomic and genetic diversity of the peninsula to establish conservation strategies and future management plans in the area. We quantified the number of species along 20 transects within the park and in the surrounding areas. In addition, we measured the genetic diversity in five phylogenetically unrelated species, using AFLP markers. A total of 90 species were recorded, $78 \%$ native and $22 \%$ non-native. The highest species richness was found in the EBT area, having significance difference with the rest of the sampling sites. The genetic analysis showed similar values of genetic diversity than previously reported for species with similar biological traits and for the same studied species, in different zones of their distribution. Therefore, high levels of species richness and genetic diversity were found in the EBT. This could be as a result of the management and protection by the university. Considering the presence of
\end{abstract}


endangered species within the EBT and the spatial distribution of species richness in the area, we recommend that the park Pedro del Rio Zañartu and surrounding areas need to be part of the areas protected by the government.

KEYwORDS: Native Relict, species richness, genetic diversity, conservation.

\section{INTRODUCCIÓN}

Existe plena conciencia que el explosivo crecimiento de las poblaciones humanas y sus efectos locales, regionales y globales han provocado graves problemas ambientales (Ojeda 1998). Factores tales como la fragmentación de hábitats, el cambio climático y la degradación de ambientes están influenciando la distribución y abundancia de especies a partir de factores directos e indirectos frecuentemente impredecibles (Primm \& Raven 2000, Bellard et al. 2012). Por otro lado, una de las consecuencias más dramáticas es el deterioro de la diversidad biológica en todos sus niveles (Woodruff 2001, Kameswara 2004). En este escenario, decidir qué conservar y dónde hacerlo es un problema de difícil solución.

Tradicionalmente, uno de los principales criterios para definir qué conservar se ha focalizado en la preservación de hotspots de biodiversidad, es decir, zonas que albergan una alta concentración de especies endémicas (al menos 0,5\% del total global) y que hayan experimentado una drástica disminución de hábitats (Myers et al. 2000). No obstante, uno de los avances en relación a las estrategias de conservación es su conceptualización de conservar no solo a una especie en particular o su diversidad genética, sino que también considerar a la comunidad en la cual se encuentran inmersas (Fitzpatrick \& Keller 2014, Weinig et al. 2014). Este enfoque permite conservar las especies en peligro, e incorpora la dinámica evolutiva del sitio. En consecuencia, las áreas de protección resguardan no solo la riqueza de especies, sino que también la riqueza genética que poseen el conjunto de las especies que coexisten (Vandergast et al. 2008).

Entendiendo que no solo la extinción de especies lleva a la pérdida de la diversidad biológica, se ha propuesto el análisis de la variabilidad genética para conservar y estudiar los procesos que mantienen y generan dicha biodiversidad (Myers \& Knoll 2001, Forest et al. 2007, Latta 2008). Los procesos evolutivos que modifican la variabilidad, y por ende, la diversidad biológica a nivel genético son las mutaciones, deriva, flujo génico y selección de especies (Lewontin 1974, Eguiarte 1999). Estos procesos denominados en su conjunto procesos microevolutivos, generan variación a nivel de individuos y poblaciones a través del cambio en las frecuencias alélicas (Filipchenko 1927), y constituyen un factor importante en la adaptación de las especies a diferentes ambientes. La pérdida de diversidad genética (variabilidad alélica) en poblaciones naturales, reduce la capacidad de las especies para evolucionar y hacer frente a cambios ambientales (Frankham 2003, Meirmans et al. 2011). Por lo tanto, la conservación de la diversidad genética, permite que las especies mantengan su potencial de adaptarse a cambios ambientales (Jay et al. 2012, Lasky et al. 2012).

Se ha señalado que la riqueza de especies y la diversidad genética están correlacionadas positivamente debido a la influencia paralela de los factores ambientales (e.g. área, conectividad y heterogeneidad ambiental) en ambos niveles de diversidad (Kahilainen et al. 2014). Sin embargo, son escasos los estudios que hayan evaluado de manera conjunta estos dos aspectos, existiendo un ejemplo en plantas alpinas (ver Taberlet et al. 2012), estudio en el cual no se encontró dicha correlación. De acuerdo a esta hipótesis, las zonas de transición climática presentarían altos valores de endemismo, riqueza específica y variabilidad genética, debido a la amplitud de variables climáticas y ecológicas que poseen (Smith et al. 2001).

En Chile, una zona de transición climática importante se ubica en la Región del Bío-Bío ( $\left.36^{\circ} \mathrm{S}\right)$. Para esta zona se ha descrito un alto nivel de endemismo (Villagrán et al. 1995, Villagrán \& Hinojosa 1997a, 1997b) y una alta riqueza de especies (Cavieres et al. 2005). Esta zona a su vez, se encuentra altamente amenazada debido a la drástica reducción del bosque nativo, el cual ha experimentado una reducción del 64\% (Lara et al. 2012). Esta zona de transición climática se encuentra inmersa en el hotspot de diversidad descrito para Chile por Myers et al. (2001), determinado en función de las particularidades de su flora y fauna (altos niveles de endemismos) y a la fuerte presión producto del cambio del uso de suelo (pérdida de hábitats) en estas regiones del país (Arroyo et al. 2004). A partir de 1996 se han propuesto para esta zona numerosos sitios prioritarios para la conservación (Muñoz et al. 1996, Cavieres et al. 2005, Ibarra-Vidal et al. 2005). No obstante, hasta el día de hoy no existe un marco legal que permita conservarlos.

Ante la urgencia de conservación en la región, decidir qué conservar y dónde hacerlo requiere de los mayores esfuerzos para evitar la pérdida de especies, comunidades y su inherente variabilidad genética. En este contexto la Península de Hualpén es uno de los últimos relictos de vegetación nativa en la zona costera de la región del Bío-Bío (Polymeris 1995). Entre sus formaciones vegetales destaca el Bosque Caducifolio de Concepción (Gajardo 1994), el cual cubría la Cordillera de la Costa en la región, no obstante, fue reemplazada por cultivos agrícolas y plantaciones forestales (CONAF http:// www.conaf.cl/parques/reserva-nacional-nonguen/) y en 
la actualidad, en la Región del Bío-Bío, solo se encuentra protegido un 3,4\% del bosque nativo por el Sistema Nacional de Áreas Silvestres del Estado (Lara et al. 2012). En cuanto a su flora, cabe destacar la presencia de especies endémicas, de distribución restringida y en peligro de conservación como son Pitavia punctata Molina y Gomortega keule (Molina) Baillon (Muñoz et al. 1996). A su vez, desde el punto de vista faunístico posee sitios de nidificación de aves migratorias, además de la presencia de mamíferos como son Dromiciops glirioides Thomas (1894), Myocastor coypus Molina (1782), especies también con problemas de conservación (Consejo de Monumentos Nacionales http://www.monumentos.cl/ catalogo/625/w3-article-26236.html).

De acuerdo a lo anterior y considerando que han pasado 40 años de haber sido declarada Santuario de la Naturaleza y 20 años desde el último estudio de vegetación en la Península, el objetivo del presente trabajo fue evaluar la distribución de la riqueza y diversidad de especies vegetales en la península centrándose en aquellas áreas que aún conservan vegetación nativa, determinando a su vez, la variación genética en las áreas de mayor riqueza y diversidad de especies nativas. Con estos resultados se contribuirá al desarrollo de estrategias de conservación y futuro desarrollo de planes de manejo en la península.
Área de estudio

La Península de Hualpén se ubica en el borde costero de la Bahía de Concepción entre los $36^{\circ} 45^{\prime}-36^{\circ} 49^{\prime} \mathrm{S}$ y los $73^{\circ} 09^{\prime}$ - 73¹3’O (Fig. 1). En 1976 fue declarada Santuario de la Naturaleza, ante la necesidad de conservar los ecosistemas que estaban bajo una fuerte presión antrópica (Polymeris 1995, Decreto $\mathrm{N}^{\circ} 556$ del Ministerio de Educación, Ley $\mathrm{N}^{\circ}$ 17.288 de Monumentos Nacionales).

La vegetación de la península incluye comunidades boscosas, donde entran en contacto especies del bosque esclerófilo con especies del bosque costero higrófilo (Polyméris 1995). La convergencia de estas comunidades ha sido explicada, en parte, por su ubicación dentro de la zona de transición entre los climas mediterráneo y templado, gradiente climático que abarca latitudinalmente desde los $36^{\circ} 00^{\prime}$ hasta los $38^{\circ} 30^{\prime} \mathrm{S}$ y longitudinalmente desde los $71^{\circ} 00^{\prime} O$ hasta el Océano Pacífico (Di Castri \& Hajek 1976). El libre acceso a las diferentes áreas de la península y la presencia de predios privados han fomentado la reducción de la cobertura de especies nativas, la colonización de especies introducidas y el aumento de plantaciones como Pinus radiata D. Don y Eucalyptus globulus Labill. (Fig. 1).

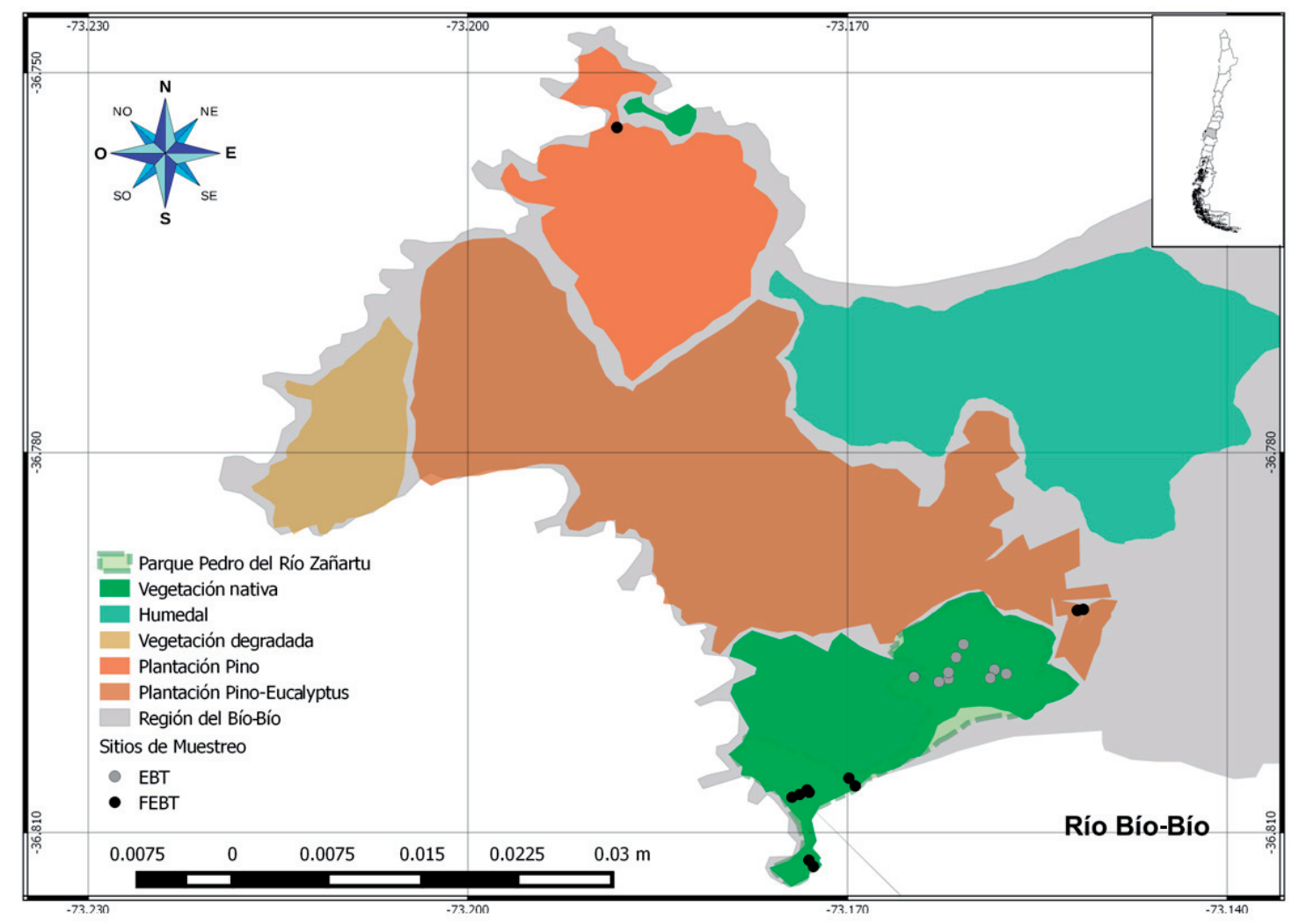

Figura 1. Mapa de la Península de Hualpén, con detalle de los sitios de muestreo, con polígonos de cobertura vegetal. / Map of the Hualpen Peninsula, with detail of samples sites, and polygons of vegetation cover. 
Al sur de la península, próximo a la desembocadura del río Bío-Bío y en dirección hacia los acantilados de Rocoto se ubica el Parque Pedro del Río Zañartu (Fig. 1). $\mathrm{Al}$ interior del parque se distingue el sector en el cual se ubica la Estación de Biología Terrestre de 89 ha, fundada en el año 1970 y que fue cedida en comodato a la Universidad de Concepción por parte de la Gobernación de Concepción. Periódicamente la Estación de Biología Terrestre, en adelante EBT, se encuentra sujeta a labores de manejo destinados a favorecer la mantención de la flora nativa. Entre las principales acciones que se realizan se encuentran la restricción del tráfico de público, eliminación de especies introducidas, mantención y reducción de senderos y exclusión de animales domésticos.

RIQUEZA Y DIVERSIDAD TAXONÓMICA

Para evaluar la distribución de la riqueza y diversidad de plantas vasculares en la península se realizó un muestreo en 20 sitios distribuidos aleatoriamente: 9 en la EBT, 8 en el sector de la desembocadura y 3 en el resto de la península (Fig. 1). Los sitios muestreados corresponden a sectores donde la vegetación no presentaba signos de perturbación reciente y se escogieron de forma independiente de la presencia de especies introducidas. No se muestreó localidades dominadas por plantaciones forestales, cultivos o zonas con un alto grado de degradación en la vegetación (Fig. 1).

En cada sitio se realizó un transecto lineal de $20 \mathrm{~m}$, en donde se registró los puntos de intersección de las distintas especies vegetales. Con esto se determinó riqueza y abundancia de las especies en cada sitio. Para evaluar el esfuerzo de muestreo, se realizaron curvas de rarefacción, donde se contrastó la riqueza de especies observada y esperada para el área de estudio, utilizando el índice de Mao Tau y Chao 1, respectivamente (Colwell \& Coddington 1994). Para determinar si existían diferencias significativas entre las curvas de valores observados y esperados se utilizaron los intervalos de confianza al 95\%. Los análisis de rarefacción se realizaron con el programa EstimateS 8.2 (Colwell 2009).

Los nombres científicos y clasificación taxonómica de las especies registradas se establecieron de acuerdo a Stevens (2001 en adelante). Las especies se clasificaron de acuerdo a su origen en nativas e introducidas siguiendo lo establecido por Zuloaga et al. (2008).

La cobertura de las especies se estimó contabilizando los puntos de intersección de los individuos en el transecto. Los valores de cobertura se utilizaron para estimar la diversidad de los sitios en términos de heterogeneidad y equitatividad. La heterogeneidad de los sitios se midió mediante el índice de Shannon-Wiener (H) (énfasis en especies raras) y el índice de Simpson (D) (énfasis en especies comunes). La equitatividad de los sitios se evaluó utilizando el índice de equitatividad de Shannon (J) (Anexo 1). Debido a que los datos no cumplían con los supuestos de normalidad y homogeneidad de varianza, las comparaciones se realizaron mediante la prueba no-paramétrica de Wilcoxon con el programa R-project (R Core Team 2014).

Para visualizar las relaciones de distancia entre sitios se realizó un análisis de agrupamiento UPGMA (Unweighted Pair Group Method with Arithmetic Mean). La matriz de distancia (euclidiana) entre sitios se confeccionó a partir de las variables número de especies nativas y número de especies introducidas por sitio. Para evaluar la composición de especies de los grupos obtenidos en el análisis de agrupamiento, se realizaron comparaciones de medias entre los valores de especies totales, especies nativas y especies introducidas por sitio. Todos estos análisis se desarrollaron con los paquetes Agricolae y pvclust para R-project (R Core Team 2014). Para evaluar las diferencias entre sitios de muestreo en función de su composición (nivel comunitario) se efectuó un análisis de escalamiento multidimensional no métrico (siglas en inglés NMS, MDS o NMDS). La matriz de distancia Bray-Curtis se confeccionó a partir de los datos de cobertura por transecto. El análisis se llevó a cabo mediante el paquete Vegan 2.3-5.tar.gz para R-project ( $\mathrm{R}$ Core Team 2014).

\section{DIVERSIDAD GENÉTICA}

En la península existen numerosos sitios que se encuentran inmersos en una matriz con severa perturbación antrópica, generándose zonas de vegetación nativa discontinuas y con menor número de especies arbóreas y arbustivas, e interrumpidas por caminos y senderos. En su conjunto estas alteraciones podrían afectar la variabilidad genética dentro de los parches nativos, por ejemplo por el efecto de deriva génica debido a la reducción de los tamaños poblacionales, especialmente en las especies herbáceas, no siendo tan evidente en las especies longevas. Debido a esto, previa a la obtención de muestras para los análisis genéticos se realizó una clasificación cualitativa de la vegetación de la península para determinar las zonas de mayor riqueza y abundancia de especies nativas.

De acuerdo a la categorización de los sitios de la península, el análisis de la diversidad genética se realizó en ejemplares localizados dentro de la ETB, a través de la estimación de la variabilidad genética en un grupo de taxa no relacionados filogenéticamente, ya que esto garantiza la evaluación de la diversidad dentro de los distintos componentes (diferentes niveles taxonómicos) siguiendo lo propuesto por Vandergast et al. (2008). Entre los criterios de selección de las cinco especies evaluadas se consideró: la representación de grupos taxonómicos distantes, su representación (abundancia y frecuencia) en el área evaluada, la inclusión de hábitos de crecimiento diferentes, la factibilidad de acceso para la toma de muestras y el fácil reconocimiento taxonómico en terreno (Tabla 1). En este estudio se utilizaron especies diploides ya que el uso de poliploides puede resultar en una sobreestimación 
de la diversidad genética, debido a los mecanismos de reparación del genoma (e.g. genes silenciados en cromosomas duplicados) (Ohno 1972, Comai 2000). Las especies seleccionadas fueron: Blechnum hastatum Kaulf., Aextoxicon punctatum Ruiz et Pav., Luma apiculata (DC.) Burret, Cissus striata Ruiz et Pav. y Lapageria rosea Ruiz et Pav. (Tabla 1). Para cada especie se muestrearon 40 individuos con una distancia promedio de $5 \mathrm{~m}$ entre ellos, para evitar el muestreo de clones. Los individuos fueron geo-referenciados y las muestras, consistentes en hojas nuevas de cada especie, fueron almacenadas en sílica gel para su posterior análisis. Para evaluar la correlación entre la diversidad genética y el tamaño de la muestra de cada especie se realizó un test de Pearson, el cual no mostró diferencias significativas para ninguno de los estimadores de diversidad genética $(p<0,050)$.

\section{EXTRACCIÓN DE ADN}

La extracción de ADN total se realizó utilizando un protocolo modificado del método CTAB (Doyle \& Doyle 1987). El protocolo involucra una limpieza de la muestra con el buffer Sorbitol ( $0,35 \mathrm{M})$, para eliminar el exceso de polisacáridos (Tel-Zur et al. 1999). La calidad del ADN fue comprobada en geles de agarosa al $1 \%$ y se realizó la dilución de las muestras para el análisis de AFLP en la proporción 1:5, diluyendo con agua nano pura (Hasbún et al. 2012). Las muestras se almacenaron a $-20^{\circ} \mathrm{C}$ hasta ser usadas en los análisis de AFLP.

AMPLIFICACIÓN AFLP y GENOTIPIFICACIÓN

La técnica de AFLP (Amplified Fragment of Length Polymorphism) se realizó siguiendo el protocolo optimizado por Hasbún et al. (2012). En la amplificación selectiva se utilizaron partidores con las mismas secuencias que los partidores preselectivos más 3 bases adicionales. Se probaron 22 combinaciones de marcadores AFLP. La selección de las combinaciones a utilizar fue verificada en geles de agarosa al $2 \%$. Se realizó una búsqueda preliminar de la mejor combinación, evaluando la cantidad de fragmentos, nitidez e intensidad de los fragmentos amplificados entre 50 y 500 pares de bases (pb). Los protocolos fueron estandarizados en los Laboratorios de Sistemática Molecular del Departamento de Botánica de la Facultad de Ciencias Naturales y Oceanográficas y Laboratorio de Epigenética de la Facultad de Ciencias Forestales, ambos de la Universidad de Concepción. Los productos de amplificación selectiva fueron corridos en un secuenciador automático (Applied Biosystem 3130, 16 capilares) en el Laboratorio de Genómica Forestal del Centro de Biotecnología de la Universidad de Concepción.

Sobre la base de los electroferogramas de AFLP obtenidos, se construyó una matriz binaria de datos (ausencia / presencia de bandas), con GeneMarker ${ }^{\circledR}$ The Biologist Friendly Software (Trial Versión http://www. softgenetics.com/downloads.php). Se consideraron aquellas bandas entre 100 y $450 \mathrm{bp}$, que presentaron una buena intensidad y definición, con al menos $1 \mathrm{bp}$ de diferencia entre ellas. Adicionalmente, se realizó un chequeo visual de cada uno de los perfiles para reducir el número de falsos positivos (Bonin et al. 2007, Turner et al. 2013). Luego se determinó la presencia de loci que estaban presentes en solo un individuo para ser eliminados del análisis, según lo recomendado por Bonin et al. (2004). La matriz final para todas las combinaciones se unificó y fue utilizada para los análisis de diversidad genética.

\section{Estadísticos DE DIVERSIDAD GENÉTICA}

Para estimar la diversidad genética a nivel de especie se utilizaron los siguientes índices: heterocigosidad esperada (He) (Nei 1973), riqueza alélica mediante el Número de alelos diferentes $(\mathrm{Na})$, Número de alelos efectivos por locus $(\mathrm{Ne})$, Índice de Shannon $(I)$ y el Porcentaje de loci polimórficos AFLP ( $\% P$ ). Todos los índices fueron calculados con el programa GenAlEx versión 6.5 (Peakall $\&$ Smouse 2012). Para evaluar las diferencias estadísticas en los valores de los parámetros de diversidad entre especies, se realizó un análisis de varianza (ANOVA de una vía) y Test HSD (Honestly-significant-difference) de Tukey en el programa R con el paquete Rcmdr (Fox 2005).

TABLA 1. Categorías taxonómicas y algunas características biológicas de las seis especies utilizadas en el estudio de variabilidad genética. / Taxonomic categories and some biological traits of the six species employed in genetic variability study.

\begin{tabular}{llllll}
\hline ESPECIE & CLASE & ORdEN & FAMILIA & 2n & HÁBITO \\
\hline Blechnum hastatum & Filicopsida & Filicales & Blechnaceae & 66 & Hierba terrestre (Perenne) \\
Luma apiculata & Magnoliopsida & Myrtales & Myrtaceae & 22 & Arbusto o árbol (Perenne) \\
Gevuina avellana & Magnoliopsida & Proteales & Proteaceae & 26 & Árbol (Perenne) \\
Aextoxicon punctatum & Magnoliopsida & Berberidopsidales & Aextoxicaceae & 32 & Arbusto o árbol (Perenne) \\
Cissus striata & Magnoliopsida & Vitales & Vitaceae & $34 *$ & Liana (Perenne) \\
Lapageria rosea & Liliopsida & Liliales & Philesiaceae & 30 & Enredadera (Perenne) \\
\hline *Este valor corresponde a la especie Cissus sulcicaulis (Baker)Planch. & & & \\
\hline
\end{tabular}




\section{RESULTADOS}

DiversidAD TAXONÓMICA

Para los 20 puntos de muestreo seleccionados (T1-T20) (Fig. 2), se encontró un total de 90 especies de plantas vasculares, pertenecientes a 79 géneros, 46 familias y 28 ordenes (Anexo 2). El $78 \%$ de las especies registradas son nativas y el $22 \%$ corresponden a especies introducidas. Cabe destacar que de las nativas registradas, el $29 \%$ son endémicas para Chile. El $80 \%$ de las especies nativas registradas se encuentran localizadas principalmente en el sector de la EBT (T1-T6) (Fig. 2). En cuanto a las curvas de rarefacción, los valores registrados no muestran diferencias entre lo esperado y lo observado (Anexo 3), y a pesar que las curvas no alcanzan la asíntota el muestreo realizado en la península es representativo de la diversidad taxonómica de esta.

Los mayores valores para los índices de diversidad de especies se encuentran fuera de la EBT en los sitios T9 y T14 (Tabla 2), los cuales presentan, a su vez los índices más altos de equitatividad (J), sin embargo, en este último sitio se encuentra una mayor proporción de especies introducidas en relación a los puntos que están dentro de la EBT.

Los resultados obtenidos para el total de las especies muestran que la riqueza de la peninsula mostró un mayor promedio de especies nativas dentro de la $\mathrm{EBT}(\mathrm{W}=78,5$, $\mathrm{p}=0,002$ ). A su vez, los sitios dentro de la EBT muestran los índices más altos de diversidad (H y D). No obstante, al comparar los índices de diversidad (H y D) y equitatividad entre los grupos dentro de la estación (EBT) y fuera de la estación de Biología Terrestre (FEBT), no se encuentran diferencias significativas para ninguno de ellos $(\mathrm{H}: \mathrm{W}=66$, $\mathrm{p}=0,051 ; \mathrm{D}: \mathrm{W}=60, \mathrm{p}=0,153$ y $\mathrm{J}: \mathrm{W}=44, \mathrm{p}=0,904)$.
Al comparar los mismos grupos (EBT y FEBT), pero realizando el análisis solo con las especies nativas, se encuentra una mayor riqueza de especies y mayor diversidad en los sitios de la EBT, sin embargo, la equitatividad sigue sin mostrar diferencias significativas (Fig. 3).

De acuerdo al análisis de agrupamiento en base a la riqueza de especies nativas e introducidas de cada transecto, se obtuvo 2 grupos de sitios (Fig. 4). El primer grupo constituido por T1-T6, T9 y T14 (Grupo rojo), corresponde a sitios que poseen principalmente especies nativas $(93 \%$ del total de especies nativas registradas en este estudio) y el segundo (Grupo azul) constituido por los sitios restantes, los cuales albergan una mayor proporción de especies introducidas, estando representado el $90 \%$ del total de especies introducidas registradas. Pese a las diferencias en la composición de especies de los sitios que forman los grupos, solo se observan diferencias significativas en el número de especies nativas $(\mathrm{W}=71, \mathrm{p}=0,004)$ y en el número total de especies por sitios $(\mathrm{W}=70, \mathrm{p}=0,005)$. A su vez, no se observaron diferencias significativas entre el número de especies introducidas entre los grupos ( $\mathrm{W}=$ $17, p=0,064)$. Cabe destacar que en la conformación del Grupo Azul se incluye a los sitios T7 y T8, que aunque solo presentan especies nativas, el número total de éstas está por debajo de la media general de los sitios (3 y 4 especies, respectivamente; media $=7$ especies).

De acuerdo al análisis de ordenamiento (MDS), se puede distinguir la conformación de dos grupos $($ Stress $=0,045$ ) con diferencias significativas en solo uno de los ejes (Fig. 5). Los grupos identificados son concordantes con la diferenciación de sitios al interior de EBT (T1-T6) y fuera de la EBT (T7-T20). Los sitios de la EBT presentan poca diferenciación entre ellos a diferencia de los sitios fuera de la EBT los cuales son muy diferentes entre sí.

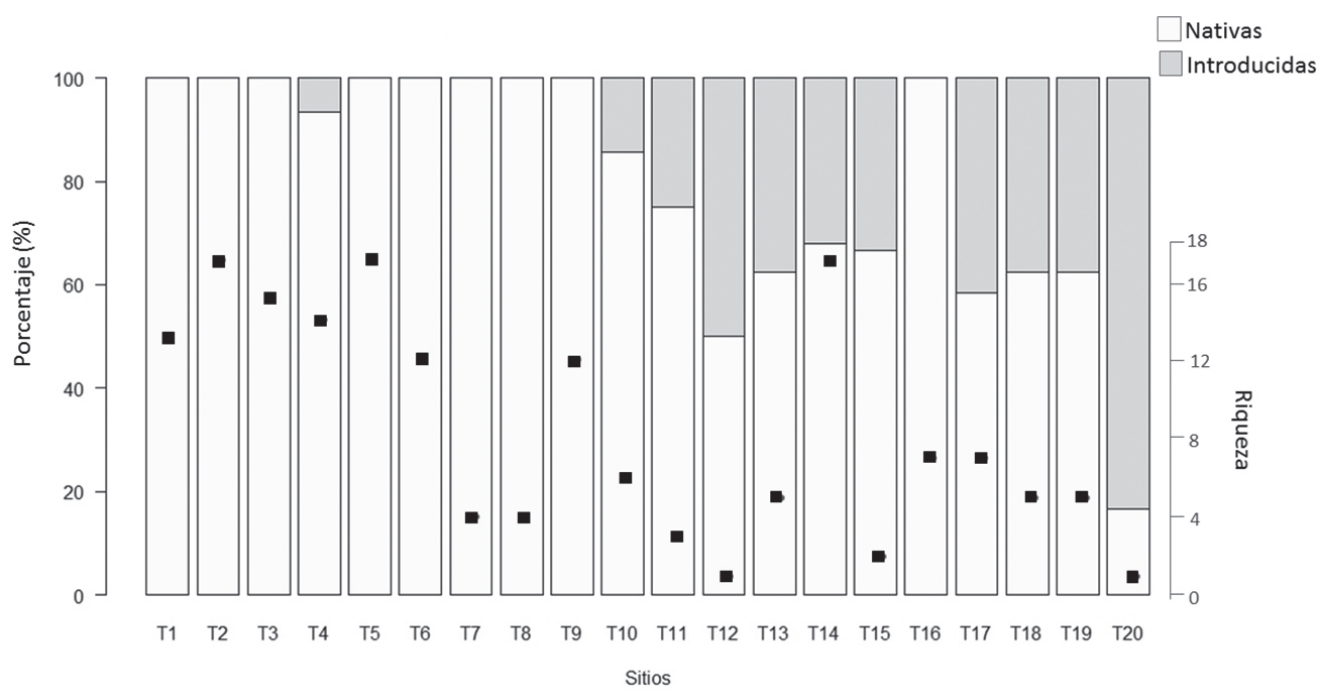

FIGURA 2. Gráfico de la distribución de porcentaje de especies nativas e introducidas para cada transecto. / Graph of percentage distribution of native and introduced species of each transect. 
DiVERSIDAD GENÉTICA

El número de individuos muestreados fue 40, sin embargo, el número de individuos analizados varió de 36 a 12, debido a problemas de extracción o amplificación. Para las tres combinaciones de partidores (Eco AGG/ MseGAC; Eco ATA/ Mse CTG y Eco AGG/Mse GAC) se obtuvo un total de fragmentos amplificados (bandas) que varió entre 115 en Blechnum hastatum a 266 en Lapageria rosea.

Los mayores valores de diversidad genética para los índices de $\mathrm{He}, I$ y $\mathrm{Ne}$ se encontraron en B. hastatum y Aextoxicon punctatum, en tanto Cissus striata muestra los menores valores en todos los índices salvo en $\mathrm{Na}$. Los valores de $P \%$ muestran una tendencia diferente, registrando el menor porcentaje en $B$. hastatum y el mayor en A. punctatum (Tabla 3).
El análisis de medias muestra que en todos los estimadores de diversidad genética existen diferencias significativas entre especies (He: $F=15.55 p<0,001 ; \mathrm{I}: \mathrm{F}=20,57 \mathrm{p}<0,001$; Ne: $\mathrm{F}=10.89, \mathrm{p}=<0,001 ; N a: \mathrm{F}=47,95, \mathrm{p}<0,001)$, siendo $B$. hastatum la única que muestra diferencias significativas con el resto de las especies (Anexo 3). En particular, para la $H e$ e $I$ no se registraron diferencias significativas entre Luma apiculata - A. punctatum, L. apiculata - C. striata y Lapageria rosea - Luma apiculata $(\mathrm{p}>0,05)$. Para $\mathrm{Ne}$ además de las tres combinaciones anteriores se agregan $C$. striata $-A$. punctatum ( $>00,05)$, finalmente el patrón de $\mathrm{Na}$ no registra diferencias entre C. striata - A. punctatum, Luma apiculata - A. punctatum y L. apiculata - C. striata $(\mathrm{p}>0,05)$.
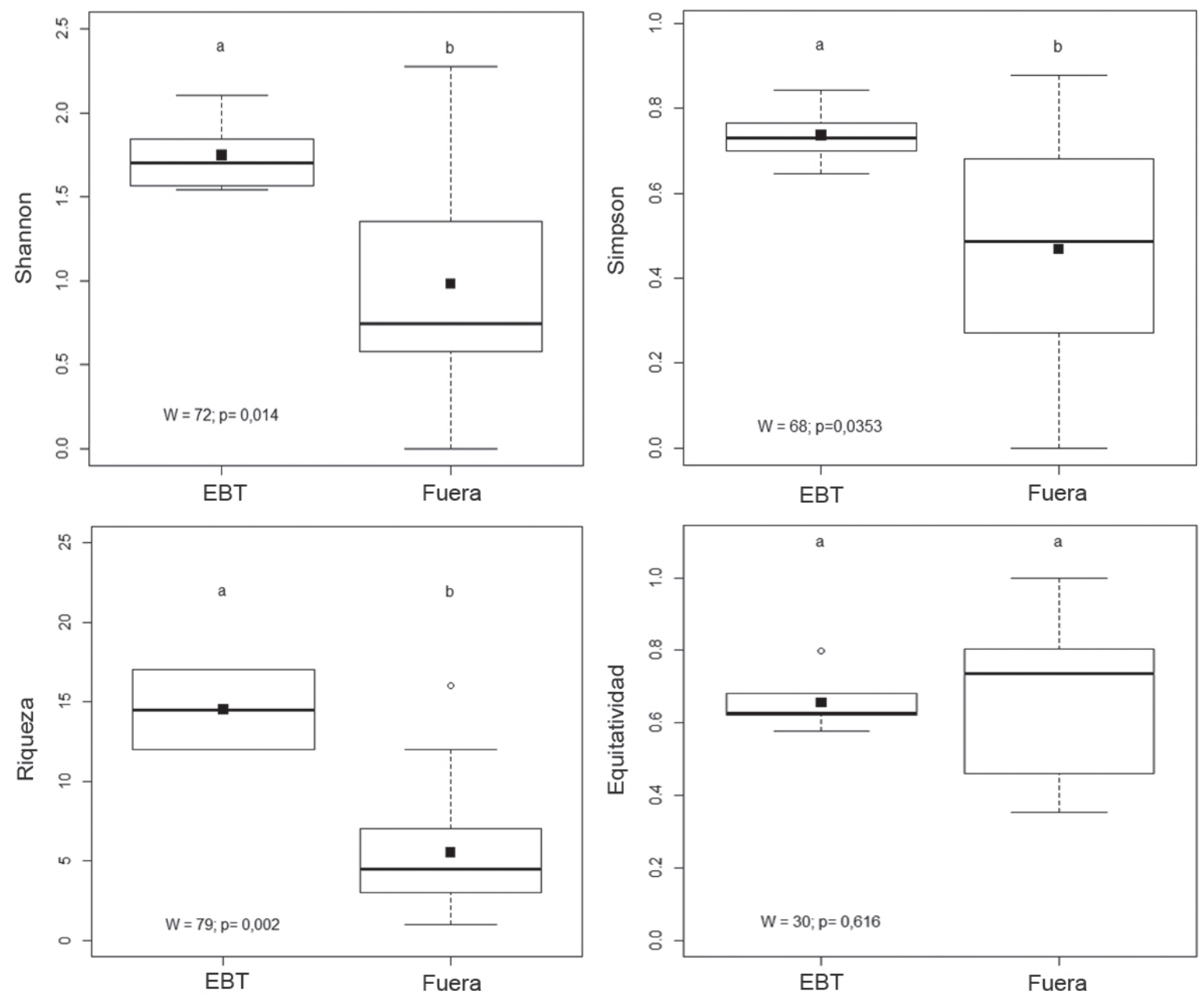

FIgURA 3. Gráficos de caja que muestran las diferencias de las variables: riqueza, índices de diversidad y equitatividad, entre los grupos dentro de EBT y fuera de ETB. Se incluye los valores del Test no paramétrico de Wilcoxon (W) y su significancia (valor-p). Los análisis solo consideran la abundancia de especies nativas. / Box plot graph showing mean differences among variables: species richness, biodiversity index and evenness, between inside EBT and outside EBT. Wilcoxon (W) non parametric test and its significance (p-value) are included. Analyses consider abundance for native species only. 
TABLa 2. Valores de diversidad, para sitio de muestreo, determinados a través de los índices de diversidad de Shannon (H) y Simpson (D), y de equitatividad de Shannon (J). Grupos de sitios: Estación de Biología Terrestre (EBT) y Fuera de Estación de Biología Terrestre (FEBT). / Diversity values for sampling sites determinate from Shannon (H), Simpson (D) index and Shannon evenness (J). Groups of sites: Terrestial biological station (EBT) and Outside Terrestrial Biological Station (FEBT).

\begin{tabular}{lcccc}
\hline SITIO & $\mathrm{H}$ & $\mathrm{D}$ & $\mathrm{J}$ & GRUPOS DE SITIOS \\
\hline T1 & 1,550 & 0,699 & 0,604 & EBT \\
T2 & 1,635 & 0,646 & 0,577 & EBT \\
T3 & 1,846 & 0,765 & 0,682 & EBT \\
T4 & 2,117 & 0,844 & 0,782 & EBT \\
T5 & 1,770 & 0,752 & 0,625 & EBT \\
T6 & 1,565 & 0,707 & 0,630 & EBT \\
T7 & 0,690 & 0,424 & 0,498 & FEBT \\
T8 & 0,489 & 0,245 & 0,353 & FEBT \\
T9 & 2,207 & 0,878 & 0,888 & FEBT \\
T10 & 1,570 & 0,758 & 0,807 & FEBT \\
T11 & 0,846 & 0,484 & 0,610 & FEBT \\
T12 & 0,192 & 0,091 & 0,277 & FEBT \\
T13 & 1,801 & 0,804 & 0,866 & FEBT \\
T14 & 2,819 & 0,919 & 0,876 & FEBT \\
T15 & 1,099 & 0,667 & 1,000 & EBT \\
T16 & 1,226 & 0,579 & 0,630 & EBT \\
T17 & 1,402 & 0,622 & 0,564 & EBT \\
T18 & 1,274 & 0,666 & 0,612 & FEBT \\
T19 & 0,657 & 0,599 & FEBT \\
T20 & 0,558 & 0,593 & FEBT \\
\hline
\end{tabular}

TABla 3. Estadísticos de diversidad genética intra-poblacional para cada una de las especies en estudio. Número de individuos $\left(\mathrm{N}^{\circ}\right)$, Número de alelos diferentes ( $\mathrm{Na}$ y y Número de alelos efectivos (Ne), Índice de Shannon (I), Heterocigosidad esperada (He), Porcentaje de loci polimórficos (P\%). / Within-population genetic diversity statistic's for each studied species. Number of Individuals $\left(\mathrm{N}^{\circ}\right)$, Rare alleles number (Na), Effective number of alleles (Ne), Shannon's Index (I), Expected Heterozygosity (He), percentage of polymorphic loci (P\%).

\begin{tabular}{lcccccc}
\hline EsPECIE & $\mathrm{N}^{\mathrm{o}}$ & $\mathrm{Na}$ & $\mathrm{Ne}$ & $\mathrm{I}$ & $\mathrm{He}$ & $\mathrm{P} \%$ \\
\hline Cissus striata & 33 & 1,965 & 1,286 & 0,32 & 0,195 & 98 \\
EE & & 0,018 & 0,019 & 0,014 & 0,01 & \\
Blechnum hastatum & 30 & 1,896 & 1,325 & 3,353 & 0,22 & 94 \\
EE & & 0,014 & 0,028 & 0,02 & 0,012 & \\
Luma apiculata & 19 & 1,958 & 1,269 & 0,321 & 0,194 & 97,9 \\
EE & & 0,024 & 0,02 & 0,014 & 0,011 & \\
Lapageria rosea & 27 & 1,976 & 1,288 & 0,333 & 0,202 & 98,1 \\
EE & & 0,07 & 0,012 & 0,012 & 0,009 & \\
Aextoxicon punctatum & 20 & 1.986 & 1,328 & 0,362 & 0,255 & 99,3 \\
EE & & 0,014 & 0,023 & 0,014 & 0,012 & \\
\hline Media & & 1,956 & 1,299 & 0,406 & 0,211 & 97,43 \\
EE & & 0,035 & 0,026 & 1,35 & 0,026 & 2,02 \\
\hline
\end{tabular}




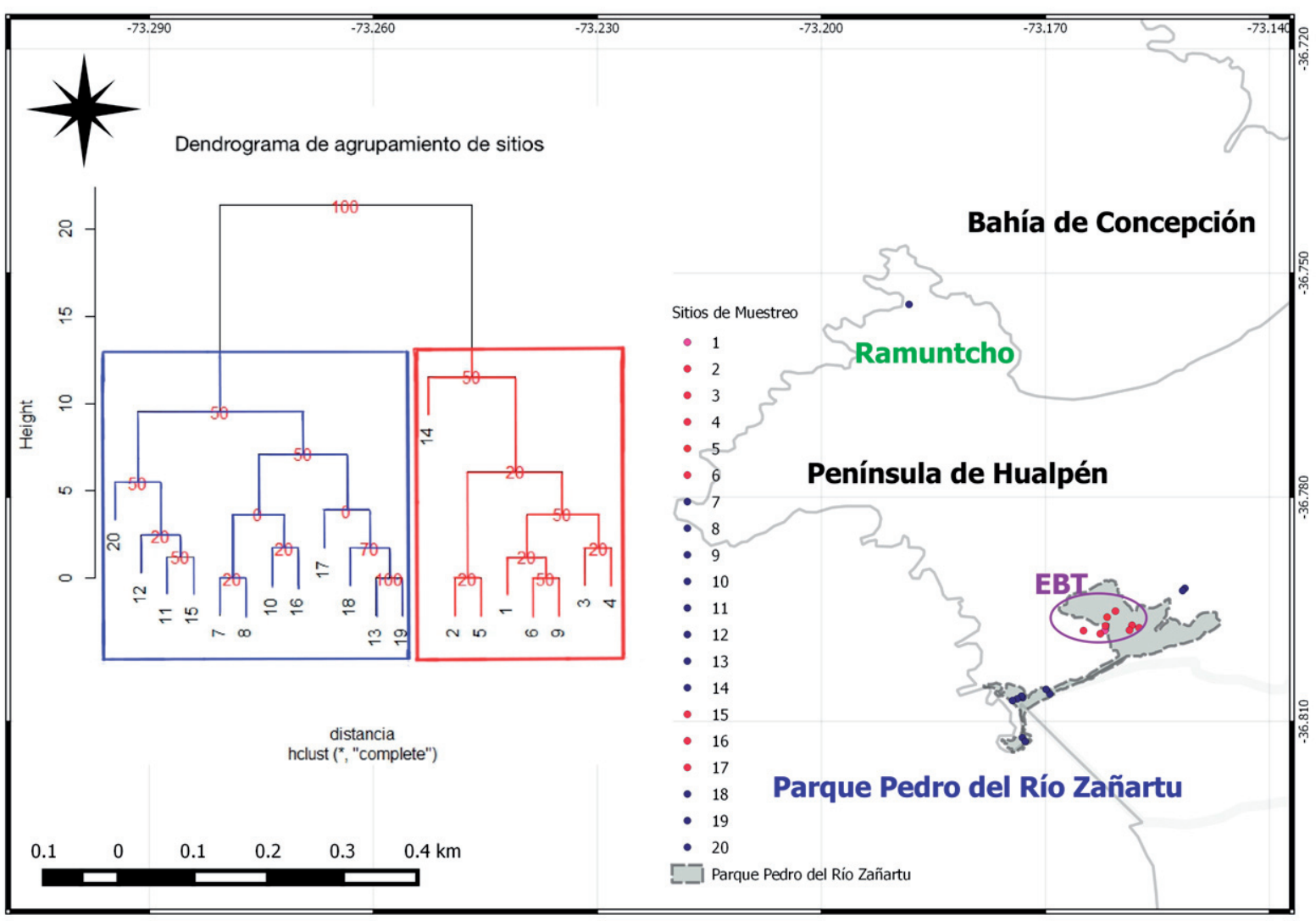

Figura 4. Dendrograma de agrupamiento y mapa de distribución de sitios de muestreo. Puntos rojos indican sitios ubicados dentro de la EBT (Estación de Biología Terrestre) y pertenecientes al Grupo 1. Puntos azules indican sitios ubicados fuera de la EBT (tanto dentro como fuera del parque Pedro del Río Zañartu), pertenecientes al Grupo 2. / Dendrogram grouping and distribution map of samples sites. Red dots indicate sites located within EBT (Estación de Biología Terrestre) belonging to Group 1. Blue dots indicate sites located outside EBT (including within and out of Pedro del Río Zañartu park) belonging to Group 2.

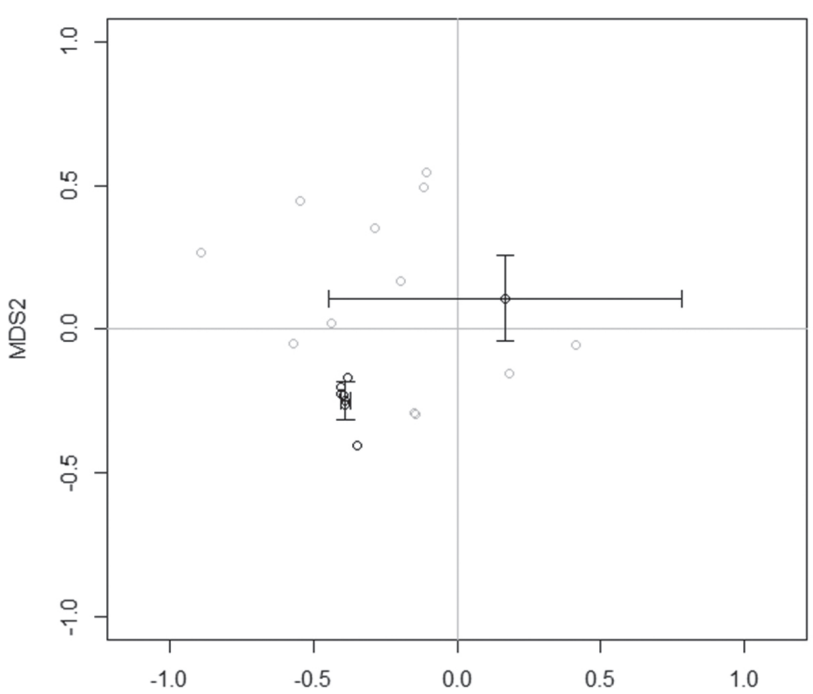

FIGURA 5. Escalamiento multidimensional no métrico realizado a partir de la matriz de abundancia de especies nativas e introducidas encontradas en cada uno de los sitios. Los círculos negros corresponden a los sitos encontrados dentro de la EBT y los círculos grises corresponden a los sitios fuera de la EBT. En negro la media de los vectores de similitud. Las barras corresponden a \pm 2 errores estándar. / Nonmetric multidimensional scaling performed using the matrix of abundance of native and non-native species found in each site. Black circles represent sampling sites within EBT and gray circles represent sampling sites outside EBT. The mean of similitude vectors is shown in bold types. Bars represent \pm 2 standard errors. 


\section{DISCUSIÓN}

De acuerdo a nuestros resultados la distribución espacial de la riqueza y la diversidad de especies en la península de Hualpén es heterogénea, destacándose la diversidad de especies y formaciones vegetales incluidas en la Estación de Biología Terrestre de la Universidad de Concepción. A nivel específico, cuando se considera el total de especies registradas, los índices de riqueza y diversidad, aunque son mayores en los de la EBT, no son significativamente diferentes al resto de los sitios de la península. Sin embargo, cuando se evalúa la distribución de solo las especies nativas, estas diferencias se hacen significativas (Número de especies, $\mathrm{H}$ y D significativamente mayor en la EBT, $\mathrm{p}>0,05)$.

Por otro lado, la composición de especies en los diferentes sitios considerados da cuenta de la heterogeneidad de sus comunidades, pudiendo reconocerse dos grandes grupos: aquellas comunidades en las que las especies nativas corresponden al componente principal (en nuestro trabajo, representadas por los sitios T1-T6) y aquellas en donde las especies introducidas son las que cobran relevancia (sitios T9-T20). De esta forma, la introducción de especies en la península altera las comunidades nativas cambiando sus características intrínsecas (e.g. composición y estructura). Consecuentemente, la disimilitud de los sitios en el análisis de ordenamiento (dispersión en los dos ejes del MDS) permitiría considerar que en la mayor parte de los sitios predominan las especies introducidas, pudiendo ser considerados, cada uno de ellos, como comunidades diferentes. Del total de especies introducidas registradas, el $75 \%$ corresponden a especies invasoras para Chile (Fuentes et al. 2014), las cuales por definición modifican el paisaje que habitan (Lockwood et al. 2007). Los patrones aquí encontrados son consistentes con la idea de que cuando las especies invasoras invaden comunidades nativas cambian su composición, estructura y diversidad (Mack et al. 2000, Pauchard et al. 2014).

De acuerdo a Polymeris (1995) la heterogeneidad entre las comunidades de la península, puede deberse a la fragmentación y degradación progresiva de la vegetación boscosa experimentada en sus comunidades. Diversos estudios han mostrado que la fragmentación es uno de los principales responsables de la pérdida de especies en ecosistemas terrestres (Saunders et al. 1991, Vitousek 1994). Del mismo modo, se ha asociado a la fragmentación y pérdida de hábitat con la reducción del tamaño poblacional (Burkey 1989). Se sabe que en poblaciones pequeñas y aisladas existe una mayor probabilidad de perder variación genética por pérdida de alelos (Ellstrand \& Ellam 1993, Frankham et al. 2003). Sin embargo, nuestros resultados muestran que la fragmentación que ha experimentado la península de Hualpén, durante las últimas décadas, parece no haber afectado los valores de diversidad genética de las comunidades vegetales que alberga la EBT. En este sentido, los valores de diversidad genética en términos de $H e$, reportados en este estudio, muestran que $B$. hastatum, $L$. rosea y $C$. striata alcanzan valores similares a los reportados en el trabajo de Nybom (2004) para especies con el mismo tipo de reproducción, ciclo de vida y distribución geográfica. No obstante, para las especies arbóreas A. punctatum y L. apiculata se registran valores levemente menores a los enunciados por este autor. Consistentemente, al comparar nuestros resultados con los reportados por Torres-Díaz et al. (2013) en el Parque Coyanmahuida, las especies Lapageria rosea, Luma apiculata, A. punctatum y C. striata presentan valores de $\mathrm{He}$ similares, en tanto que nuestros resultados en términos de $P \%$ son incluso mayores $(C$. striata $H e=0,215$, $P \%=98 ;$ Lapageria rosea $\mathrm{He}=0,212, \mathrm{P} \%=79 ;$ A . punctatum $H e=0,227, P \%=77,4 ;$ Luma apiculata $H e=0,211, P \%=95,6)$.

Es así como este trabajo da cuenta de dos aspectos importantes para la conservación, en primer lugar la necesidad de establecer medidas de mantención y protección de la diversidad de flora nativa, a través de estrategias de conservación efectiva por medio del Estado de Chile. La no inclusión de las formaciones vegetales de la península de Hualpén en el SNASPE ha fomentado la introducción de especies, el aumento de la superficie de plantaciones y el aumento del número de parches y disminución de la superficie promedio de cada uno (Lara et al. 2012, Miranda et al. 2017). Pese a ello los valores de diversidad de especies y genética que posee EBT muestran la efectividad del manejo que se ha hecho hasta la fecha por parte de la entidad a cargo de este terreno, cabe destacar que esta es la única zona sujeta a manejo. En segundo lugar, deja en evidencia la necesidad de realizar más estudios que permitan actualizar la información sobre el estado de la flora del lugar y la diversidad genética de los distintos grupos de plantas presentes y su interacción con los parámetros ecológicos de la zona. Además, realizar estudios de diversidad genética fuera de la EBT que permitan evaluar, por ejemplo, la hipótesis que plantea que la riqueza de especies y la diversidad genética están correlacionadas positivamente (Kahilainen et al. 2014) y así visualizar si efectivamente las zonas protegidas poseen mayor diversidad genética que las zonas no protegidas. Con ello se podría no solo evaluar el hecho que zonas sometidas a manejo conservan de mejor manera ambos aspectos de la diversidad biológica, sino que además permitirían la elaboración de planes de manejo adecuados que incluyan ambos niveles de la diversidad, para recuperar áreas que registren menores valores de uno o ambos componentes (taxonómico y/o genético).

Por lo tanto, de acuerdo a los resultados obtenidos, la EBT necesita ser mantenida fortaleciendo los planes de manejo que se han dado hasta la fecha, y se recomienda ampliar la evaluación de nuevos sitios en sectores aledaños que puedan ser incorporados para potenciar la conectividad entre parches de vegetación nativa. Se recomienda además incluir o considerar las características genéticas de las 
especies presentes en este sector en futuras estrategias de conservación, específicamente aquellas que incluyan restauración in situ, en especial dentro de la EBT. Por último y debido a los antecedentes del rápido efecto que tienen factores como el cambio climático global sobre la variabilidad genética de las especies vegetales (Bellard et al. 2012), se recomienda establecer parcelas permanentes de monitoreo con el fin de evaluar cómo se ve afectada la diversidad en todos sus niveles ante este tipo de alteraciones.

Finalmente, es necesario destacar que la evaluación de la riqueza de especies y la diversidad genética de las comunidades, tradicionalmente se ha abordado de manera independiente, y este estudio muestra la importancia de realizar evaluaciones conjuntas de los dos niveles de diversidad dentro y entre las zonas de interés para la conservación.

\section{AGRADECIMIENTOS}

Se agradece el financiamiento del PROYECTO DIUC $\mathrm{N}^{\circ}$ 211.111.057-1.0. Administración de la Reserva Hualpén, en especial a don Ricardo León, por su valiosa ayuda en los muestreos y a Dra (C) María Moreno por sus revisiones y comentarios.

\section{REFERENCIAS}

Arroyo, M.T.K., Marquet, P., Marticorena, C., Simonetil, J., Cavieres, L., Squeo, F.A., Rozzi, R. 2004. Chilean winter rainfall-valdivian forests. In: R.A. Mittermeier, P. Robles Gil, M. Hoffmann, J. Pilgrim, T. Brooks, C. Goettsch, J. Lamoreux \& G.A.B. da Fonseca (eds.), "Hotspots Revisited", pp. 99-103. CEMEX, México.

Bellard, C., Bertelsmeier, P., Leadley, W., Huiller T., Courchamp, F. 2012. Impacts of climate change on the future of biodiversity. Ecology Letters 15: 365-377.

Bonin, A., Bellemain, E., Broken Eidesen, P., Pompanin, F., Crochamann, C., Taberle, P. 2004. How to track and assess genotyping error in population genetic studies. Molecular Ecology 13: 3261-3273.

Bonin, A., Ehrich, D., Manel, S. 2007. Statistical analysis of amplified fragment length polymorphism data: a toolbox for molecular ecologists and evolutionists. Molecular Ecology 16: 3737-3758.

BurKeY, T.V. 1989. Extinction in nature reserves: the effect of fragmentation and the importance of migration between reserve fragments. Oikos 55: 75-81.

Cavieres, L., Mihoc, M., Marticorena, A., Marticorena, C., Baeza, M., Arroyo, M. 2005. La Flora vascular de la Cordillera de la Costa en la Región del Bio-Bío: patrones de distribución de riqueza de especies, géneros familias y endemismos. En: Smith-Ramírez, C., Armesto, J.J., Valdovinos, C. (eds.), Historia, Ecología y Biodiversidad de la Cordillera de Costa de Chile. pp. 245-253. Editorial Universitaria S.A., Santiago, Chile.
Colwell, R.K. 2009. EstimateS: Statistical estimator of species richness and shared species from samples. Version 8.2. User's Guide and application published at: http://purl.oclc. org/estimates

Colwell, R., Coddington, J. 1994. Estimating Terrestrial Biodiversity through Extrapolation. Philosophical Transaction Biological Sciences. 345: 101-118.

ComaI, L. 2000. Genetic and epigenetic interactions in allopolyploid plants. Plant Molecular Ecology 43: 387-399.

Di Castri, F., Hajer E. 1976. Bioclimatología de Chile. Ediciones de la Pontificia Universidad Católica de Chile Santiago. Chile. 129 pp.

Doyle, J.J., Doyle, J.L. 1987. A rapid DNA isolation procedure for small quantities of fresh leaf tissue. Phytochemical Bulletin 19: 11-15.

Eguiarte, L. 1999. Una guía para principiantes a la genética de poblaciones. En: J. Nuñez-Farfán \& L.E. Eguiarte (eds.), La Evolución Biológica. pp. 35-50. Facultad de Ciencias, Instituto de Ecología, UNAM, CONABIO. México.

Ellstrand, N., Elan, D. 1993. Population genetic consequences of small population size: implications for plant conservation. Annual Review of Ecology and Systematics 24: 217-242.

FILIPCHENKO, I.A. 1927. Variabilitat und variation (Variability and variation). Gebrüder Bromtraeger, Berlin.

FitzPatrick, M., Keller, S. 2014. Ecological genomics meets community-level modelling of biodiversity: mapping the genomic landscape of current and future environmental adaptation. Ecology Letters 18: 1-16.

Forest, F., Grenyer, R., Rouget, M., Davies, T., Cowling, R., Faith, D., Balmford, A., Manning, J., Proches, S., Van der Bank, M., Reeves, G., Hedderson, T., Savolainen, V. 2007. Preserving the evolutionary potential of flora in biodiversity hotspots. Nature 445: 757-760.

Fox, J. 2005. The R Commander: A Basic Statistics Graphical User Interface to R. Journal of Statistical Software 14: 1- 42.

Frankham, R. 2003. Genetic and conservation biology. Comptes Rendus Biologies 326: S22-S29.

FrankHAM, R. 2005. Genetics and extinction. Biological Conservation 126: 131-140.

Fuentes, N., Sánchez, P., Pauchard, A., Urrutia, J., Cavieres, L., Marticorena, A. 2014. Plantas Invasoras del Centro-Sur de Chile: Una Guía de Campo. Laboratorio de Invasiones Biológicas (LIB), Concepción, Chile. 276 pp.

GAJARDO, R. 1994. La vegetación natural de Chile: clasificación y distribución geográfica. Editorial Universitaria, Santiago, Chile. 165 pp.

Hamrick, J.L., Godt, M.J.W. 1996. Effects of life history traits on genetic diversity, in plant species. Philosophical Transactions Biological Sciences 1345: 1291-1298.

Hasbun, R., Iturra, C., Moraga, P., Wachtendorff, P., Quiroga, P., Valenzuela, S. 2012. An efficient and reproducible protocol for production of AFLP markers in tree genomes, using fluorescent capillary detection. Tree Genetics \& Genomes 8: 925-931.

Ibarra-Vidal, H., Sepúlveda, C., Saavedra, D., Maldonado, E. 2005. Propuesta de conservación de los bosques nativos en la cordillera costera del Maule y Bío-Bío (VII y VIII regiones). En: Smith-Ramírez, C., Armesto, J.J., Valdovinos, C. (eds.), Historia, Ecología y Biodiversidad de la cordillera de la Costa de Chile. Pp. 617-631. Editorial 
Universitaria S.A. Santiago, Chile.

Jay, F., Manel, S., Alvarez, N., Durand, E.Y., Thuiller, W., Holderegger, R., Taberlet, P., Francois, O. 2012. Forecasting changes in population genetic structure of alpine plants in response to global warming. Molecular Ecology 21: 2354-2368.

Kahilainen, A., Puurtinem, M., Kotiaho, J. 2014. Review paper Conservation implications of species-genetic diversity correlations. Global Ecology and Conservation 2: 315-323.

KameswarA, R. 2004. Plant genetic resources: Advancing conservation and use though biotechnology. African Journal of Biotechnology 3(2): 136-145.

Lara, A., Solari, M., Prieto, M., Peña, M. 2012. Reconstrucción de la vegetación y uso de suelo hacia 1550 y sus cambios a 2007 en la ecorregión de los bosques valdivianos lluviosos de Chile (35ㅇ $43^{\circ} 30^{\prime}$ S). Bosque 33(1): 13-23.

Lasky, J.R., Des Marais, D.L., McKay, J., Richards, J.H., Juenger, T.E., KeitT, T.H. 2012. Characterizing genomic variation of Arabidopsis thaliana: the roles of geography and climate. Molecular Ecology 22: 5512-5529.

LATTA, R. 2008. Conservation genetics as applied evolution: from genetic pattern to evolutionary process. Conservation Genetics as Applied Evolution 1: 84-94.

Lewontin, R.C. 1974. The Genetic Basis of Evolutionary Change. Columbia University Press, New York. 346 pp.

Lockwood, J.L., Hoopes, M.F., Marclutti, M.P. 2007. Invasion ecology. Blackwell Publishing. United Kingdom. 312 pp.

Mack, R.N., Simberloff, D., Lonsdale, W.M., Evans, H., Clout, M., Bazzaz, F. 2000. Biotic invasions: Causes, epidemiology, global consequences and control. Issues in Ecology 5: 1-25.

Marquet, P.A., Fernandez, M., Navarrete, S.A., Valdovinos, C. 2004. Diversity emerging: toward a deconstruction of biodiversity patterns. In: M. Lomolino \& L.R. Heaney (eds.), Frontiers of biogeography: new directions in the geography of nature, pp. 192-209. Sinauer Associates. Sunderland, Massachusetts. USA.

Meirmans, D., Goudet, J., Intrabiodiv Consortium, Gaggiotti, O. 2011. Ecology and life history affect different aspects of the population structure of 27 high-alpine plants. Molecular Ecology 20(15): 3144-3155.

Merilä, J., Sheldon, B., KruUK, L. 2001. Explaining stasis: micro evolutionary studies in natural populations. Genetica 112113: 199-222.

Miranda, A., Altamirano, A., Cayuela, L., Lara, A., González, M. 2017. Native forest loss in the Chilean biodiversity hotspot: revealing the evidence. Regional Environmental Change 17: 285-297.

Muñoz, M., Nuñez, H., YÁÑEz, J. 1996. Libro rojo de los sitios prioritarios para la conservación de la diversidad biológica en Chile. CONAF, Ministerio de Agricultura. Santiago, Chile. 203 pp.

Myers, N., Knoll, A.H. 2001. The biotic crisis and the future evolution. Proceedings of the National Academy of Science (USA) 98: 5389-5392.

Myers, N., Mittermeier, R.A., Mittermeier, C., Da Fonseca G.A.B., Kent, J. 2000. Biodiversity hotspots for conservation priorities. Nature 403: 853-858.

NeI, M. 1973. Analysis of genetic diversity in subdivided populations. Proceedings of the National Academy of
Sciences 70(12): 3321-3323.

Nyвom, H.D. 2004. Comparison of different nuclear DNA markers for estimating intraspecific genetic diversity in plants. Molecular Ecology 13: 1143-1155.

OHno, S. 1972. So Much “Junk” DNA in Our Genome. In: Smith, H.H. (Ed.), Evolution of Genetic Systems, Gordon and Breach, New York, 366-370.

OJEDA, F.P. 1998. Estado actual de la conservación de la diversidad biológica en Chile. Revista Chilena de Historia Natural 71: 117-120.

Pauchard, A., García, R., Langdon, B., Nuñez, M. 2014. Invasiones de plantas en ecosistemas forestales: bosques y praderas invadidas. En: C. Donoso, M. González \& A. Lara (eds), Ecología Forestal: Bases para el Manejo Sustentable y Conservación de los Bosques Nativos de Chile. pp 673691. Ediciones Universidad Austral de Chile. Valdivia, Chile.

Peakall, R., Mouse, P.S. 2012. GenAlEx 6.5: genetic analysis in Excel. Population genetic software for teaching and research an update. Bioinformatics 28: 2537-2539.

Polymeris, C. 1995. Vegetación actual de la Península de Hualpén: clasificación y dinámica. Tesis de grado de Magíster en Ciencias, Mención Botánica, Universidad de Concepción, Chile, 190 pp.

Primm, S. L., Raven, P. 2000. Biodiversity- Extintion by numbers. Nature 403: 843- 845 .

Raymond, M., Berticat, C., Weill, M., Pasteur, N., Chevillon, C. 2001. Insecticide resistance in the mosquito Culex pipiens: what have we learned about adaptation? Genetica 112-113: 287-296.

R Core Team. 2014. R: A language and environment for statistical computing. R Foundation for Statistical Computing, Vienna, Austria. URL: http://www.R-project.org/.

Saunders, D.A., Hobbs, R., Margules, C.R. 1991. Biological consecuences of ecosystem Fragmentation: A Review. Conservation Biology 5(1): 18-32.

Smith, T., Kark, S., Schneider, C., Wayne, R. 2001. Biodiversity hotspots and beyond: the need for preserving environmental transitions. Trends in Ecology \& Evolution 16(8): 431.

Stevens, P.F. (2001 en adelante). Angiosperm Phylogeny Website. Versión 12 (2012). Disponible en: http://www.mobot.org/ MOBOT/research/APweb/ (Visitado enero 2016).

Taberlet, P., Zimmemann, N., Englisch, T., Tribsch, A., Holderegger, R., Alvarez, R., Nikled, H., Coldea, G., Mirek, Z., Moilanen, A., Ahlemer, W., Ajmane, P., Boma, E., Bovio, M., Choler, P., Cièslak, E., Colli, L., Cristea, V., Dalmas, J.R., Frajman, B., Garraud, L., Gaudeul, M., Gielly, L., Gutemann, W., Jogan, N., Kagalo, A., Korbercka, G., Küpter, P., Lequette, B., Roman Letz, D., Manel, S., Mansion, G., Marhold, K., Martini, F., Neguini, R., Niño, F., Paum, O., Pellecchia, M., Perico, G., Piekós-Mirkova, H., Prosser, F., Puscas, M., Ronikier, M., Scheuerer, M., Schneeweiss, G., Schönswetter, P., Scharh-Eherndorfer, L., Schitiper, F., Selvaggi, A., Steimann, K., Thiel-Egenter, C., Van Loo, M., Winkler, M., Wohlgemuth, T., Wraber, T., Gugerli, F., IntraBioDiv Consortium. 2012. Genetic diversity in widespread species is not congruent with species richness in alpine plant communities. Ecology Letters 15: 14391448 . 
Tel-Zur, N., Abbo, S., Myslabodski, D., Mizrahi, Y. 1999. Modified CTAB procedure for DNA isolation from Epiphytic Cacti of the genera Hylocereus and Selenicereus (Cactaceae). Plan Molecular Biology Reporter 17: 249254.

Torres-Díaz, C., Ruiz, E., Salgado-Luarte, C., MolinaMontenegro, M.A., Gianoli, E. 2013. Within-population genetic diversity of climbing plants and trees in a temperate forest in central Chile. Gayana Botánica 70(1): 36-43.

Turner, B., Paun, O., Munzienger, J., Duanguai, S., Chase, M.W., SAmuel, R. 2013. Analyses of amplified fragment length polymorphism (AFLP) indicate rapid radiation of Diospyros species (Ebenaceae) endemic to New Caledonia. BMC Evolutionary Biology 13: 269.

Vandergast, A., BohonaK, A., Hathaway, S., Boys, J. 2008. Are hotspots of evolutionary potential adequately protected in Southern California? Biological Conservation 141: 16481664.

Villagrán, C., Moreno, P., Villa, R., Armesto, J. 1995. Antecedentes palinológicos acerca de la historia cuaternaria de los bosques chilenos. En: J.J. Armesto, C. Villagrán \& M.T.K. Arroyo (eds.), Ecología de los bosques nativos de Chile. Pp: 51-69. Editorial. Universitaria, Santiago, Chile.
Villagrán, C., Hinojosa, L. 1997a. Historia de los bosques del sur de Sudamérica I: antecedentes paleobotánicos, geológicos y climáticos del Terciario del cono sur de América. Revista Chilena de Historia Natural 70: 225-239.

Villagrán, C., Hinojosa, L. 1997b. Historia de los bosques del sur de Sudamérica II: Análisis fitogeográfico. Revista Chilena de Historia Natural 70: 241-267.

Vitousek, P.M. 1994. Beyond Global Warming: Ecology and Global Change. Ecology 75(7): 1861-1876.

Weinig, C., Ewers, B.E., Welch, S.M. 2014. Ecological genomics and process modeling of local adaptation to climate. Current opinion in plant Biology 18: 66-72.

Wheeler, B. 2013. SuppDists: Supplementary distributions. R package version 1.1-9.1. URL: Website http://cran.rproject.org/web/packages/SuppDists/index.html

WoodrufF, D. 2001. Declines of biomes and biotas and the future of evolution. Proceedings of Natural Academy of Sciences 98(10): 5471-5476.

Zuloaga, F.O., Morrone, O., Belgrano, M.J.(eds.). 2008. Catálogo de las plantas vasculares del Cono Sur (Argentina, sur de Brasil, Chile, Paraguay y Uruguay). Monograph Systematic Botany, Missouri Botanical Garden 107(2). URL: http:// www2.darwin.edu.ar/ Proyectos/FloraArgentina/FA.asp

ANEXo 1. Fórmulas de los índices de diversidad y equitatividad utilizados. / Biodiversity index and evenness formula used.

\begin{tabular}{lcl}
\hline \multicolumn{1}{c}{ ÍnDICE } & Símbolo & \multicolumn{1}{c}{ Fórmula } \\
\hline Índice de Shannon-Wiener & $\mathrm{H}$ & $-\sum \mathrm{p}_{\mathrm{i}} \operatorname{Ln} \mathrm{p}_{\mathrm{i}}$ \\
Índice de Simpson & $\mathrm{D}$ & $\sum \mathrm{p}_{\mathrm{i}}^{2}$ \\
Índice de Equitatividad de Shannon & $\mathrm{J}$ & $\mathrm{H} / \mathrm{Ln}(\mathrm{S})$ \\
\hline
\end{tabular}

Definiciones:

S: número de especies en la muestra

$\mathrm{p}_{\mathrm{i}}$ : proporción individuos pertenecientes a $\mathrm{i}$ especie $\left(\mathrm{p}_{\mathrm{i}}=\mathrm{n}_{\mathrm{i}} / \mathrm{N}\right.$, con $\mathrm{n}_{\mathrm{i}}=$ número de individuos de la i especie en la muestra y $\mathrm{N}=$ Total de individuos muestreados)

Ln: logaritmo natural 


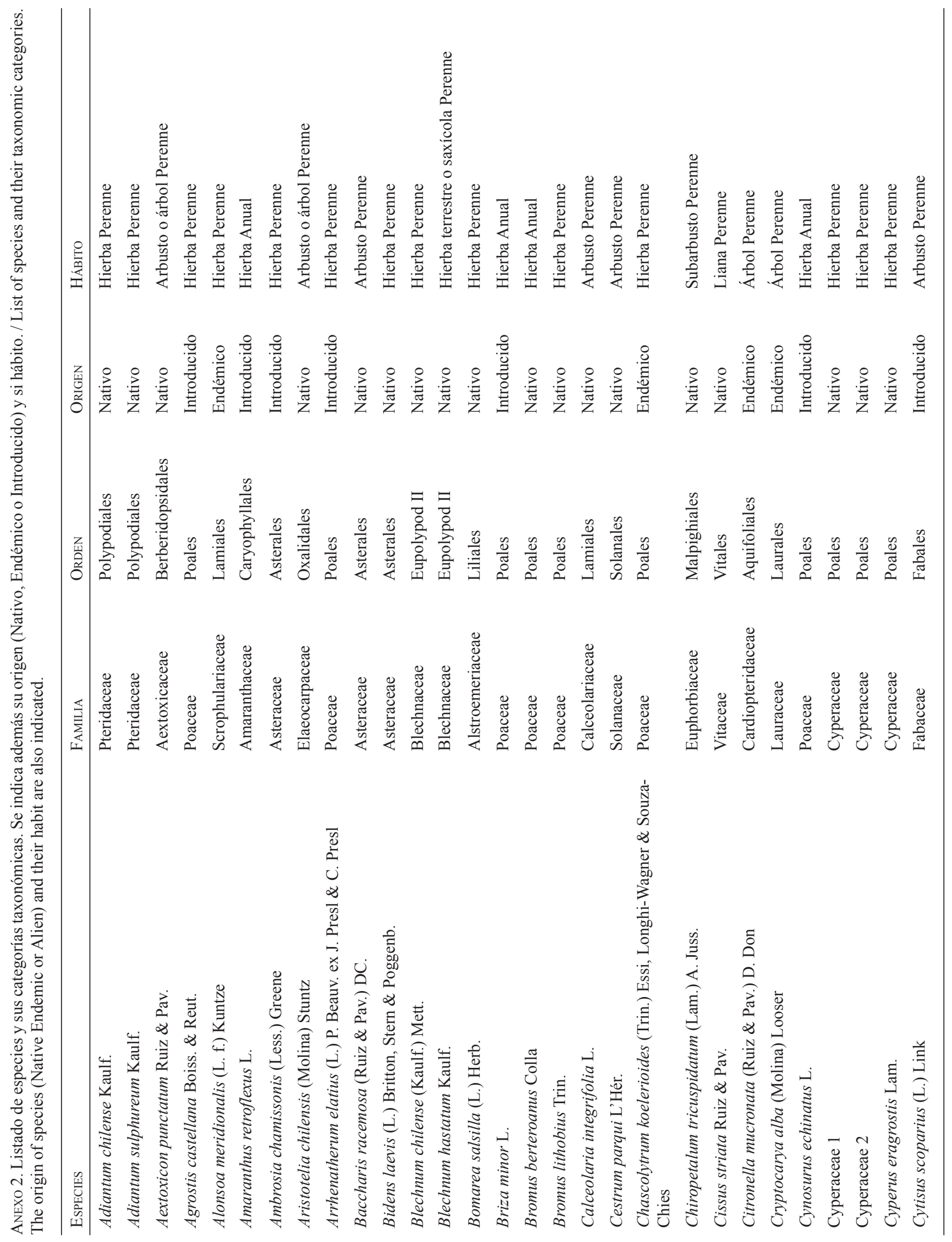



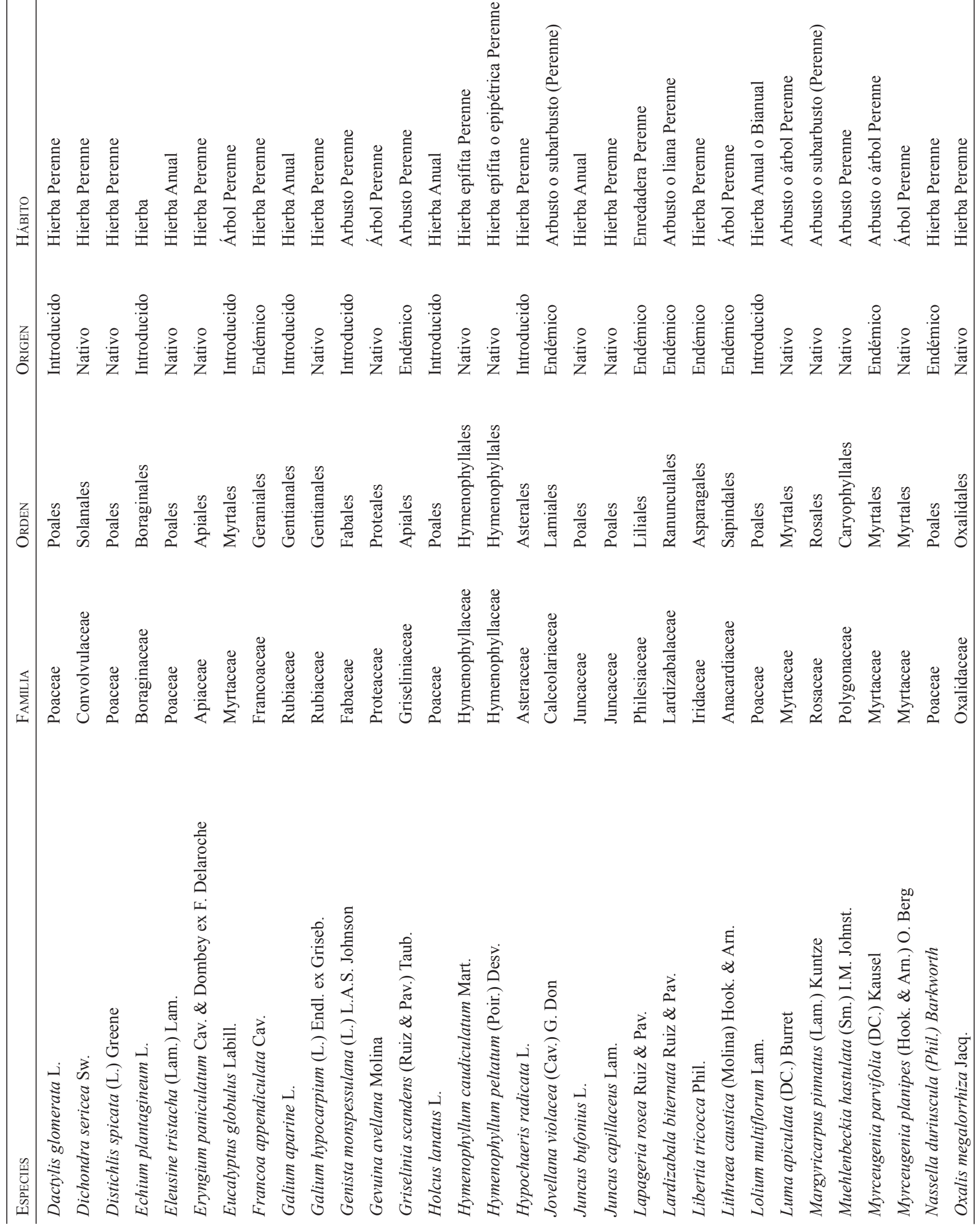


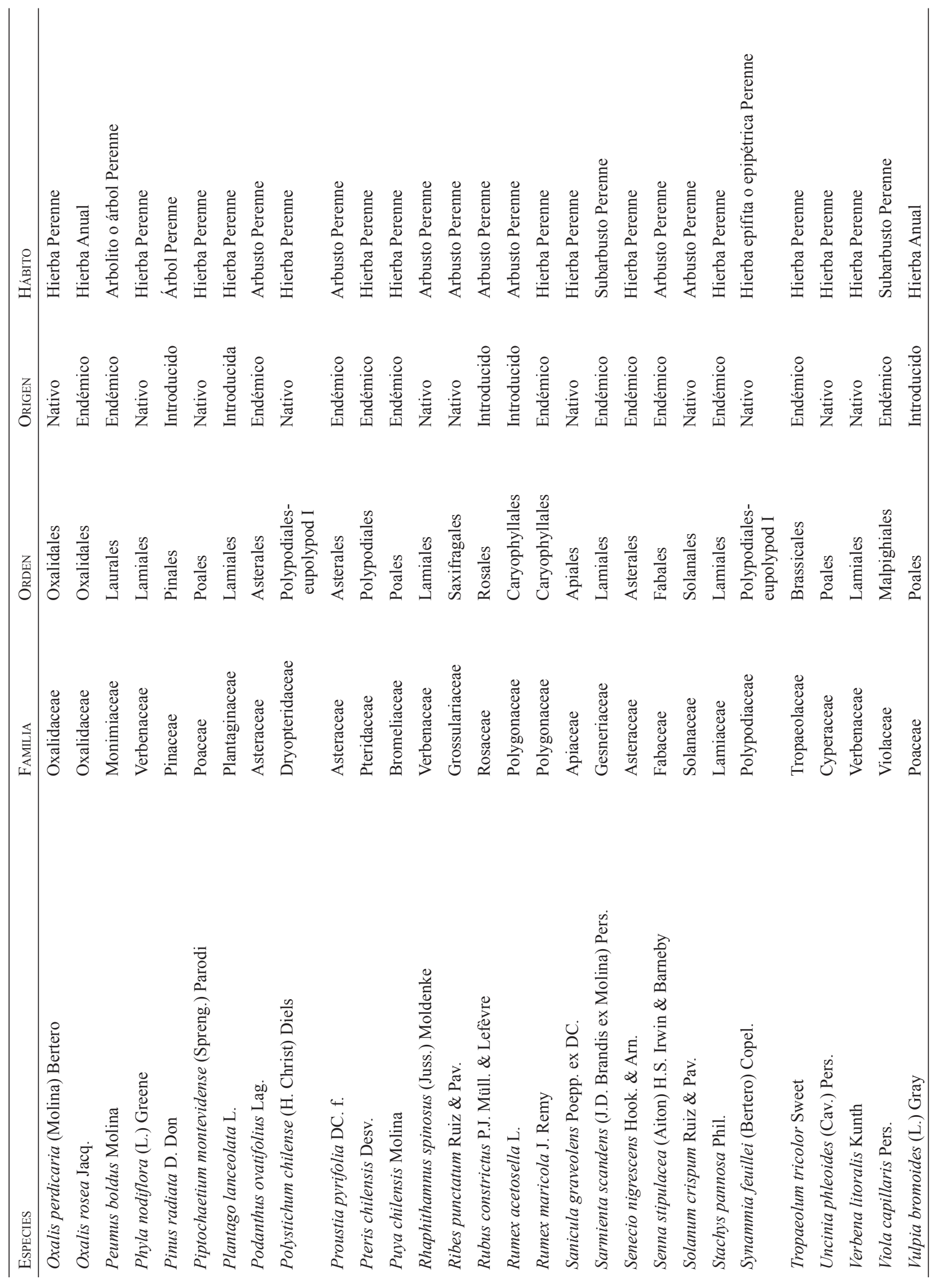


Curvas de rarefacción para la estimación del óptimo de muestro en el parque del Pedro del Río Zañartu. / Rarefaction curves for optimal estimation of the sample units in Pedro del Río Zañartu park.

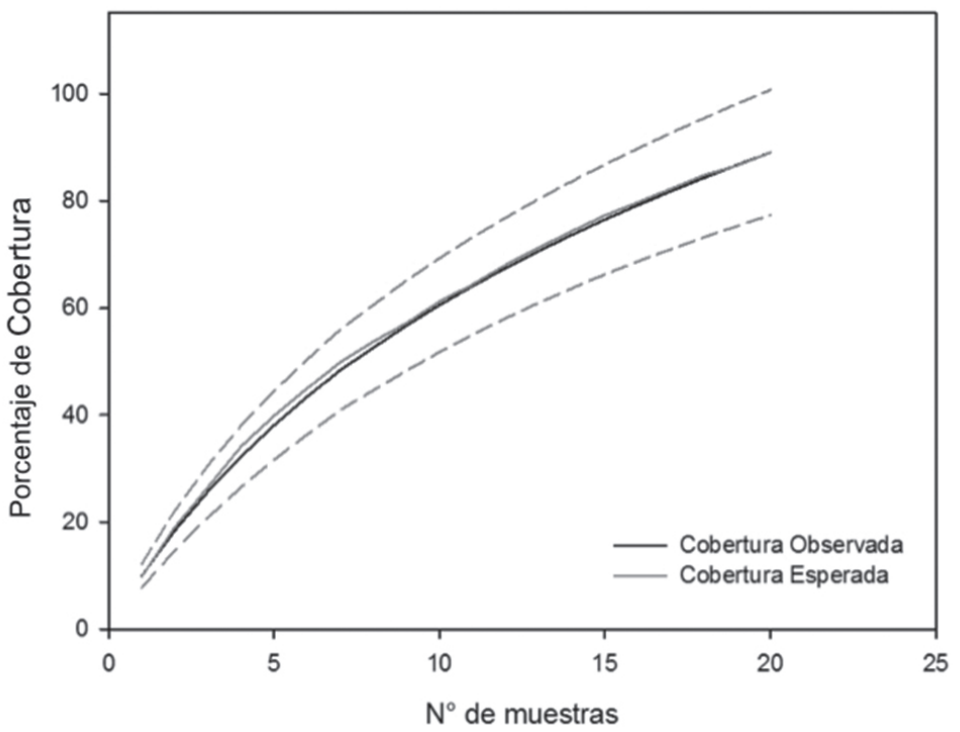

Test HSD (Honestly-significant-difference) de Tukey Valor significativo en la comparación de medias entre pares de especies. $(+=\mathrm{p}<0,05$, $-=\mathrm{p}>0,05)$. / Test HSD (Honestly-significant-difference) Tukey significant value in the comparison of means between pairs of species.

\begin{tabular}{lcccc}
\hline PARES de ESPECIES & He & I & Ne & Na \\
\hline A. punctatum-B. hastatum & + & + & + & + \\
A. punctatum-C. striata & + & + & - & - \\
A. punctatum-Lapageria rosea & - & - & - & - \\
A. punctatum-Luma apiculata & + & + & + & + \\
B. hastatum-C. striata & + & + & + & + \\
B. hastatum-Luma apiculata & + & + & + & + \\
B. hastatum-Lapageria rosea & + & + & + & + \\
C. striata-Luma apiculata & - & - & - & - \\
C. Striata-Lapageria rosea & - & - & - & + \\
Lapageria rosea-Luma apiculata & + & + & - & + \\
\hline
\end{tabular}

Recibido: 28.06.2016

Aceptado: 19.12.2016 